\title{
Efficiency of long-term high-dose intravenous ascorbic acid therapy in locally advanced basal cell carcinoma - a pilot study
}

\author{
András Bánvölgyi ${ }^{1}$, Kende Lőrincz ${ }^{1}$, Norbert Kiss ${ }^{1,2}$, Pinar Avci ${ }^{1}$, Luca Fésüs ${ }^{1,2}$, Róbert Szipőcs ${ }^{3}$, Tibor Krenács ${ }^{4}$, \\ Nóra Gyöngyösi ${ }^{1}$, Norbert Wikonkál' ${ }^{1}$, Sarolta Kárpáti ${ }^{1}$, Krisztián Németh ${ }^{1}$
}

${ }^{1}$ Department of Dermatology, Venereology and Dermatooncology, Semmelweis University, Budapest, Hungary

${ }^{2}$ Wigner RCP, Institute for Solid State Physics and Optics, Budapest, Hungary

${ }^{3}$ R\&D Ultrafast Lasers Ltd; Wigner RCP, Institute for Solid State Physics and Optics, Budapest, Hungary

${ }_{4}^{4} 1^{\text {st }}$ Department of Pathology and Experimental Cancer Research, Semmelweis University, Budapest, Hungary

Adv Dermatol Allergol 2020; XXXVII (4): 548-558

DOI: https://doi.org/10.5114/ada.2019.83027

\begin{abstract}
Introduction: The anti-cancer properties of high-dose intravenous ascorbic acid have been demonstrated in various malignancies. In our recent study, we tested topically applied ascorbic acid to treat basal cell carcinoma (BCC), and achieved a good clinical response.

Aim: Based on these results, we decided to examine the efficacy and tolerability of high-dose intravenous ascorbic acid (IVA) for locally advanced BCC.

Material and methods: In this pilot study, patients diagnosed with locally advanced BCC who were not amenable to radiation, surgical or local therapy (no other treatment option was available at the time) received intravenous ascorbic acid (1-1.8 g/kg), in an outpatient setting, 1-3 times per week for a mean duration of $42 \pm 23.6$ weeks. This therapy was generally well tolerated.

Results: Among 4 patients who had a total of 165 (mean: $41 \pm 51$, range: 1-114) skin lesions, 3 patients achieved stable disease and one had progressive disease. There was substantial variability in individual tumor response to therapy. With the aid of two-photon microscopy and second harmonic generation imaging techniques, alterations in collagen structure were observed between tumor nests during IVA therapy.

Conclusions: Our results suggest that IVA is well tolerated in a small group of patients with extensive BCCs. However, in the era of smoothened (Smo) receptor inhibitors, it may only be considered as an adjuvant therapy in treatment-resistant cases.
\end{abstract}

Key words: basal cell carcinoma, vitamin C, ascorbic acid.

\section{Introduction}

Basal cell carcinoma (BCC) of the skin is the most common cutaneous malignancy in Caucasian patients [1]. Depending on the size, subtype and location of the cancer, there are various treatment options available. These include Mohs micrographic surgery (MMS)/surgical excision, other procedural solutions such as electrodesiccation and curettage, cryotherapy, photodynamic therapy and radiation therapy as well as topical application of various immunomodulatory and antimetabolite agents [2]. The vast majority of BCCS can be cured with these modalities and MMS provides the highest cure rate among all treatments. Challenging cases with high recurrence rates and spread to adjacent musculoskeletal structures - and rarely to distant organs include large, infiltrating BCCs in the periocular and periauricular region and BCCs developing in patients with certain cancer syndromes, such as in nevoid basal cell carcinoma syndrome (BCNS, basal cell nevus or Gorlin-Goltz syndrome) [3]. To reduce the tumor burden in these patients, systemic tumor-targeted therapy is preferred.

Recently, two small-molecule inhibitors of smoothened (Smo) - vismodegib (GDC-0449, Roche) and sonidegib (LDE225, Novartis) - have been approved for this purpose. The former drug is approved to treat metastatic and locally advanced BCC, while the latter can be used to treat therapy-resistant locally advanced BCC [2, 4]. Unfortunately, they

Address for correspondence: András Bánvölgyi, Department of Dermatology, Venereology and Dermatooncology, Semmelweis University, Budapest, Hungary, phone: +36 203315142, e-mail: banvolgyi.andras@gmail.com Received: 11.01.2019, accepted: 30.01.2019. 
may have severe side effects resulting in discontinuation of therapy [5-8]. Therapeutic resistance may also occur [5-8]. At the time of our study neither vismodegib nor sonidegib was available on the European market, prompting our search for an alternative treatment option that may benefit patients with locally advanced BCCs who were either not amenable to or declined currently available treatments.

There is a growing body of evidence on the potential benefit of high-dose intravenous ascorbic acid (IVA) therapy in various malignancies, such as ovarian, pancreatic and prostate cancers [9]. If patients are selected properly, IVA is well tolerated with a negligible side effect profile compared to chemotherapeutic agents [9-12]. In addition, we recently published a study that demonstrated a possible therapeutic role of topically applied saturated ascorbic acid solution to treat BCC [13].

Two-photon excitation fluorescence (TPEF) and second harmonic generation (SHG) are novel label free optical imaging tools that may eliminate routine staining processes and are also capable of real-time in vivo imaging. TPEF microscopy can reveal endogenous fluorophores, such as $\mathrm{NAD}(\mathrm{P}) \mathrm{H}, \mathrm{FAD}$ and elastin. Subsequently, it enables visualization of the cellular structure and tissue morphology. The SHG is a specific method to observe collagen fibers. TPEF and SHG have been previously utilized to visualize and differentiate various BCC subtypes and also to discriminate BCC from squamous cell carcinoma $[14,15]$. The combination of these modalities enables us to assess fine changes of tissue pathology during IVA therapy which may not be apparent in standard hematoxylin and eosin (HE) stained histology sections.

Based on the above, we set out to investigate the use of high-dose IVA therapy in selected patients with locally advanced BCC and also to assess changes in tumor stroma by TPEF and SHG methods.

\section{Aim}

The primary objective of our study was to assess tolerability of IVA in carefully selected BCC patients. Our secondary objectives were to halt progression or induce regression of already existing tumors and inhibit new tumor development. Our tertiary objective was to assess the basic mechanisms underlying the therapeutic effect of IVA therapy.

The main criteria for protocol termination at the beginning of the study were as follows: an intolerable IVA side effect or toxicity, or deterioration of the patient's general condition such that IVA administration would not be feasible or unequivocal progression for more than three months. In the later stages of the study as vismodegib became available, even stable disease status was a reason for discontinuation.

\section{Material and methods}

This pilot study was conducted at the Department of Dermatology, Venereology and Dermato-oncology of the Faculty of Medicine, Semmelweis University Budapest, Hungary. Compounding of the intravenous vitamin $C$ solution and its off-label use were approved by the Regional Committee of National Science and Research Ethics (TUKEB 80/2010) and the National Institute for Quality and Organizational Development in Healthcare and Medicines (39.798/56/09). The study was conducted in accordance with the ethical standards as dictated by the Declaration of Helsinki and its later amendments or comparable ethical standards. This study was conducted with the human subjects' understanding and consent.

\section{Patient selection criteria}

Patients diagnosed clinically and histologically with locally advanced BCC who were not amenable to radiation, surgical or local therapies were recruited for high-dose IVA treatment. Patients eligible for the study had to meet the following inclusion and exclusion criteria (Table 1). The subjects were not required to meet the diagnostic criteria for BCNS.

\section{Patient enrollment}

We screened 6 patients with locally advanced BCC who were recruited from our oncology outpatient clinic.

Table 1. Inclusion and exclusion criteria

\begin{tabular}{ll}
\hline Inclusion criteria & Exclusion criteria \\
\hline Histologically confirmed locally advanced BCC & G6PHD enzyme deficiency \\
\hline$\geq 18$ years of age & History of chronic heart failure \\
\hline Patient not amenable to radiation, surgical or other available therapies & History of renal disease, evidence of kidney stones \\
\hline $\begin{array}{ll}\text { Patient denied radiation, surgical or other available therapies that would lead } \\
\text { to severe dysfunction and/or disfiguration }\end{array}$ & History of liver disease \\
\hline Patient did not receive any treatment for BCC $\geq 4$ weeks prior to IVA therapy & Other malignancies \\
\hline ECOG status $\leq 2$ & Pregnancy or lactation \\
\hline Normal renal function, GFR $\geq 60 \mathrm{ml} / \mathrm{min}$, serum creatinine level $<120 \mu \mathrm{mol} / \mathrm{l}$ & \\
\hline Normal liver function, total serum bilirubin $\leq 15 \mathrm{mg} / \mathrm{l} ; \mathrm{AST}<45 \mathrm{U} / \mathrm{l}, \mathrm{ALT}<55 \mathrm{U} / \mathrm{l}$ & \\
\hline
\end{tabular}


Table 2. Patient demographics and clinical data

\begin{tabular}{|c|c|c|c|c|c|}
\hline Parameter & Patient 1 & Patient 2 & Patient 3 & Patient 4 & Mean \pm SD \\
\hline Age [years] & 47 & 67 & 83 & 52 & $62.25 \pm 16.23$ \\
\hline Sex & $\mathrm{F}$ & M & M & M & \\
\hline Patient history & $\begin{array}{l}\text { NIDDM, MI, AF, fibrotic } \\
\text { type pseudotumor } \\
\text { resection of small bowel }\end{array}$ & NIDDM, HT & $\mathrm{HT}$ & None & \\
\hline Fitzpatrick skin type & Type I & Type II & Type II & Type II & \\
\hline Age at first onset of disease [years] & 24 & 53 & $\mathrm{~N} / \mathrm{A}$ & 17 & \\
\hline BCNS: & Yes & No & Yes & Yes & \\
\hline Palmar pitting & Yes & No & Yes & Yes & \\
\hline Jaw cysts & No & No & No & Yes & \\
\hline Falx cerebri calcification & Yes & No & Yes & Yes & \\
\hline $\begin{array}{l}\text { Minor BCNS criteria (musculoskeletal } \\
\text { system abnormalities, medulloblastoma, } \\
\text { intestinal tumor, ovarian fibromas, etc.) }\end{array}$ & Yes & No & Yes & No & \\
\hline Previous excessive sun exposure & No & Yes & Yes & Yes & \\
\hline Location of BCC lesions & $\begin{array}{c}\text { Scalp, face, neck, ear, } \\
\text { trunk }\end{array}$ & $\begin{array}{l}\text { Orbit, lower } \\
\text { eyelid, } \\
\text { intrasinusoidal } \\
\text { mucous } \\
\text { membrane }\end{array}$ & $\begin{array}{l}\text { Nose, forehead, } \\
\text { ear, back }\end{array}$ & $\begin{array}{l}\text { Scalp, face, neck, } \\
\text { trunk, upper } \\
\text { extremities }\end{array}$ & \\
\hline Number of BCC lesions & 42 & 1 & 8 & 114 & $41.25 \pm 51.7$ \\
\hline Previous treatment modalities & $\begin{array}{c}\text { Surgery, } \mathrm{CO}_{2} \text { laser, } \\
\text { cryotherapy, imiquimod, } \\
\text { acitretin, PDT }\end{array}$ & $\begin{array}{l}\text { Radiotherapy } \\
\text { (patient } \\
\text { refused } \\
\text { surgery or } \\
\text { enucleation) }\end{array}$ & $\begin{array}{l}\text { Surgery, } \\
\text { radiotherapy }\end{array}$ & $\begin{array}{l}\text { Surgery, } \\
\text { cryotherapy, } \\
\text { isotretinoin, } \\
\text { acitretin, PDT, } \\
\text { intralesional INF }\end{array}$ & \\
\hline
\end{tabular}

Two patients were excluded from the study, one due to history of renal stones and the other could not be followed up due to lack of compliance. Informed consent was obtained from all patients included in the study. The mean age of 4 patients (1 female, 3 males) enrolled in the study was $62.3 \pm 16.2$ years (range: $47-83$ years). Three out of 4 patients met the diagnostic criteria for BCNS [16]. For further patient demographics and clinical data see Table 2.

\section{Treatment protocol}

In general the IVA dosage was $1.8 \mathrm{~g} / \mathrm{kg}$ body weight, with treatment doses ranging from 75 to $175 \mathrm{~g}$ per infusion and administered three times a week, after a 4-week dose escalation period, as described in previous studies [11]. Occasionally there were intervals when treatment was suspended due to no show up or other medical conditions irrespective of IVA therapy. These were compensated by elevated frequency of treatment in other weeks. Mean duration of treatment was $42 \pm 23.6$ weeks. For administration of IVA we used a Port-A-Cath device for 3 of the 4 patients, as a high osmotic effect might damage peripheral veins. In the case of patient 3 a Port-A-Cath device could not be implanted initially. At this time, the dose was reduced to $1.1 \mathrm{~g} / \mathrm{kg}, 75 \mathrm{~g}$ per occasion as the maximum tolerable amount of ascorbic acid through a peripheral vein. Patient 4 completely refused the PortA-Cath device; therefore we administered $1.3 \mathrm{~g} / \mathrm{kg}, 100 \mathrm{~g}$ ascorbic acid per occasion, which was the maximum dose that this patient could tolerate via a peripheral vein (see Table 3 for a more detailed description).

The infusion solutions were prepared sterile from concentrated ascorbic acid solutions at the Department of Pharmacology of Semmelweis University. Each $50 \mathrm{ml}$ vial contained $25 \mathrm{~g}$ of ascorbic acid $(500 \mathrm{mg} / \mathrm{ml}$ ) buffered to $\mathrm{pH}$ 5.5-7 using sodium bicarbonate and edetate disodium, as described before [11]. Solutions were diluted in $1000 \mathrm{ml}$ of Ringer's lactate infusion and administered for $3 \mathrm{~h}$. The infusion solutions were protected from light at bedside.

\section{Assessment of study outcome}

Following baseline evaluation, we selected one to six measurable target lesions per patient that were monitored monthly using digital photography and image analysis. Magnetic resonance images (MRI) and com- 
Table 3. Target lesion characteristics, treatment duration and dosage

\begin{tabular}{|c|c|c|c|c|c|}
\hline Parameter & Patient 1 & Patient 2 & Patient 3 & Patient 4 & Mean \pm SD \\
\hline Number of target lesions & 6 & 1 & 5 & 6 & $4.5 \pm 2.3$ \\
\hline $\begin{array}{l}\text { Location of target } \\
\text { lesions }\end{array}$ & $\begin{array}{l}\text { Scalp, periauricular, } \\
\text { temporal, frontal and } \\
\text { mental area }\end{array}$ & $\begin{array}{l}\text { Orbit, lower eyelid, } \\
\text { intrasinusoidal } \\
\text { mucous membrane }\end{array}$ & Nose, forehead, ear & $\begin{array}{l}\text { Face, chest, right shoulder, } \\
\text { right upper arm, right and } \\
\text { left suprascapular area }\end{array}$ & \\
\hline $\begin{array}{l}\text { Subtypes of target } \\
\text { lesions }\end{array}$ & $\begin{array}{l}\text { Nodular- } \\
\text { micronodular, } \\
\text { adenoid }\end{array}$ & Infiltrative & Infiltrative & $\begin{array}{l}\text { Nodular, pigmented, } \\
\text { superficial }\end{array}$ & \\
\hline $\begin{array}{l}\text { Cumulative initial size of } \\
\text { target lesions [mm] }\end{array}$ & 301.2 & 88.1 & 43.1 & 70.7 & $125.8 \pm 118.4$ \\
\hline $\begin{array}{l}\text { Duration of treatment } \\
\text { [weeks] }\end{array}$ & 76 & 26 & 26 & 40 & $42 \pm 23.6$ \\
\hline $\begin{array}{l}\text { Number of treatments/ } \\
\text { week }\end{array}$ & $2-4$ & 3 & 3 & $1-2$ & \\
\hline $\begin{array}{l}\text { Number of treatment } \\
\text { sessions }\end{array}$ & 173 & 72 & 75 & 49 & $92.2 \pm 55.1$ \\
\hline $\begin{array}{l}\text { Maximum interval } \\
\text { between two successive } \\
\text { treatments [weeks] }\end{array}$ & 5 & 1 & 1 & 6 & \\
\hline $\begin{array}{l}\text { Usage of port-a-cat } \\
\text { device }\end{array}$ & Yes & Yes & $\begin{array}{l}\text { Yes (after } 12 \text { weeks } \\
\text { of peripheral vein } \\
\text { administration) }\end{array}$ & $\begin{array}{l}\text { No (administered via } \\
\text { peripheral vein) }\end{array}$ & \\
\hline $\begin{array}{l}\text { Maximum dose of } \\
\text { ascorbic acid/treatment }\end{array}$ & $1.8 \mathrm{~g} / \mathrm{kg} ; 175 \mathrm{~g}$ & $1.8 \mathrm{~g} / \mathrm{kg} ; 125 \mathrm{~g}$ & $\begin{array}{c}1.1 \mathrm{~g} / \mathrm{kg}, 75 \mathrm{~g} \text { (first } \\
12 \text { weeks); } 1.8 \mathrm{~g} / \mathrm{kg}, \\
125 \mathrm{~g} \text { (after } 12 \text { weeks) }\end{array}$ & $1.3 \mathrm{~g} / \mathrm{kg}, 100 \mathrm{~g}$ & \\
\hline $\begin{array}{l}\text { Cumulative dose of } \\
\text { ascorbic acid [g] }\end{array}$ & 29150 & 8970 & 7039 & 4800 & \\
\hline
\end{tabular}

puted tomography (CT) scans, if needed, were obtained to measure changes in tumor volumes or to monitor new lesion formation. We measured the longest diameter of each target lesion with Digimizer image analysis software v. 4.3 (MedCalc Software, Ostend, Belgium). We assessed cumulative target lesion size, as the sum of the longest diameter of all target lesions per patient. Then we calculated the mean lesion size of all target lesions in all patients. In order to assess the treatment response for each patient, we adapted Response Evaluation Criteria in Solid Tumors (RECIST v.1.1) guidelines [17]. Complete response was defined as disappearance of all lesions. Partial response represented a decrease of > $30 \%$ in the sum of all the longest diameters of target lesions. Progressive disease was defined as at least $20 \%$ increase in the sum of all the longest diameters of target lesions and/or appearance of a new lesion and/or an unequivocal escalation in overall disease status. Stable disease defined cases where the decrease in overall target lesion size did not qualify for complete or partial response, nor did the increase qualify for a progressive disease. As some of the lesions on the skin had an uneven surface, it was not always feasible to measure the quantitative changes in vertical dimension and calculate the tumor volume. In an attempt to better reflect these changes, cutaneous response was also assessed via a scoring system adapted and modified from Mashiah et al. and Maytin et al. [18, 19]. In this scoring system, each lesion was scored based on two parameters, change in horizontal dimension (progression $>20 \%$ increase $=-1$, stable $=0$, partial regression $>30 \%$ decrease $=1$, complete regression $=2$ ) and vertical dimension (prominent elevation = -0.5 , minor change (decrease or increase) in elevation or no change at all $=0$, prominent flattening $=0.5$ ). The score for each parameter was summed and then divided by the number of target lesions, to obtain an average score. The final score was the sum of two average scores (horizontal and vertical dimension score) for each patient, with values ranging between -1.5 and 2.5 . Patients were divided into one of four response groups as follows: complete response $=3$, partial response $=0.75-3$, stable $=0.75$ to -0.75 , progression $=-0.75$.

\section{Histopathological examinations}

Skin biopsy samples were collected before the start and after IVA treatment in the case of patients 1 and 2 . Patients 3 and 4 had a single biopsy before treatment, but did not consent to a second, follow-up biopsy. As pa- 


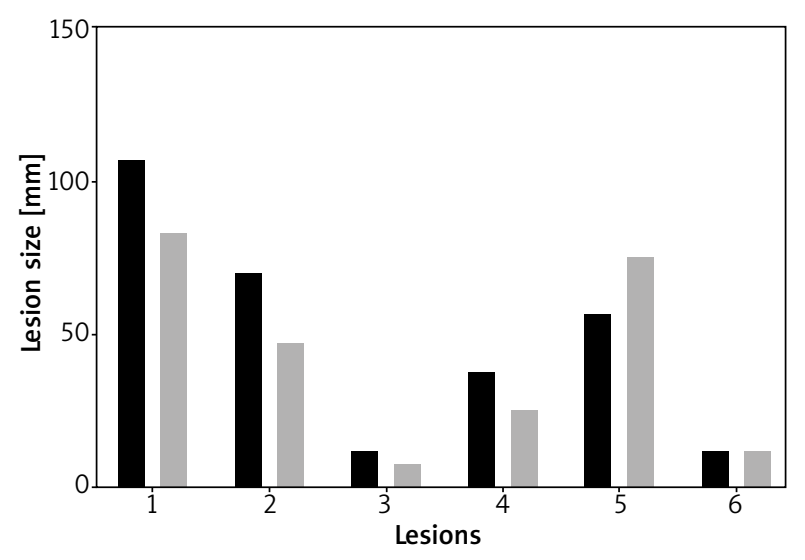

- Before treatment $\quad$ After treatment

Figure 1. Longest diameter of each lesion size of patient 1 before and after intravenous ascorbic acid (IVA) therapy. Subtypes were the following: lesion 1 (micronodular), lesion 2 (micronodular), lesion 3 (nodular), lesion 4 (micronodular), lesion 5 (micronodular), lesion 6 (adenoid)

tient 1 had numerous tumors with relatively large tumor sizes and excellent compliance, we could collect additional tumor tissue samples during the treatment period.

The HE stained sections of 10\% formalin-fixed and paraffin-embedded skin biopsy samples were evaluated for diagnostic and therapy assessment purposes. Additionally, $4 \mu \mathrm{m}$ thick sections from patient 1 were used for immunohistochemical analysis.

In an attempt to confirm the degree of vascularization in two different subtypes (micronodular and adenoid) of BCC in the same patient, staining with monoclonal mouse anti-CD31 (PECAM-1, clone: 89C2, Cell Signaling, MA, USA) was performed.

We acquired TPEF and SHG images of deparaffinized tissue samples from lesions 1 and 2 of patient 1 after a 2-week drug-free interval, and after the subsequent 2 weeks of intensive (10 sessions) IVA therapy. A custom modified Axio Examiner LSM 7 MP laser scanning two-photon microscope (Carl Zeiss AG, Germany) was used to capture the images. We applied a femtosecond pulse Ti-sapphire laser (FemtoRose 100TUN NoTouch, R \& D Ultrafast Lasers Ltd, Hungary) tuned for a $800 \mathrm{~nm}$ excitation wavelength. A 395-415 nm band-pass emission filter was used to separate the SHG signal from the TPEF signal which was collected at 565-610 nm and intracellularly attributed to mainly flavin adenine dinucleotide (FAD). The images were captured by a $20 \times$ water immersion objective (W-Plan - APOCHROMAT 20×/1.0 DIC (UV) VIS-IR, Carl Zeiss AG, Germany). The size of each field of view corresponded to $0.42 \times 0.42 \mathrm{~mm}^{2}$, from which mosaic images of larger areas up to $6.72 \times 6.72 \mathrm{~mm}^{2}$ were generated by ImageJ software (NIH, USA). The imaging setup is further described in refs. [20,21]. We selected five fields of view from the tumor nests and their associated peritumoral stroma for quantitative analysis. Changes in collagen mor- phology (fiber length and width) were assessed by CT-FIRE (v1.3) (LOCI, USA), a curvelet transform-fiber tracking algorithm in the selected field of views.

\section{Results}

We treated 4 patients who had a total number of 165 (mean: $41.25 \pm 51.7$, range: $1-114$ ) lesions. We evaluated their response to therapy, monitoring a total of 18 target lesions with a mean lesion size of 27.95 $\pm 31.90 \mathrm{~mm}$ (range: $5-108.5 \mathrm{~mm}$ ). Seventy two percentage of the lesions were located in the head and neck region, $17 \%$ on the trunk and $12 \%$ on the extremities. Mean duration of IVA treatment was $42 \pm 23.6$ weeks (Table 3 ).

Among the lesions responding to therapy, lesion size decreased by $4-16 \%$ (Table 4). However, it should be emphasized that not all lesions responded to therapy equally, and some even progressed (Figure 1).

While $83 \%$ of all target lesions responded (partial and stable response) to therapy, $17 \%$ progressed. Among the 15 lesions which responded to therapy, 27\% demonstrated a partial response and $73 \%$ had a stable response. Evaluation of overall treatment response showed stable disease for 3 patients and progressing disease for 1 patient (Table 4). On the other hand, the cutaneous lesion score showed a stable disease for all 4 patients (Table 5). Lastly, none of the patients developed any detectable new lesions.

Representative images of lesions with a notable response to treatment are presented in Figures $2 \mathrm{~A}-\mathrm{J}$. Follow-up skin biopsy taken from the nasal root region of patient showing a tumor-free scar tissue is displayed below (Figures $2 \mathrm{~K}, \mathrm{~L}$ ). In the case of patient 1, brief interruption of IVA led to tumor progression, which was controlled again when the treatment was restarted.

There was no nephrolithiasis or any other significant adverse event during IVA treatment. Solely mild nausea (grade 1) occurred occasionally in patient 1 . A slight burning sensation occurred during the administration of ascorbic acid through the peripheral vein in patient 3 and patient 4 (grade 1).

In patient 1 and patient 3 progression of some lesions could not be completely stopped. As the Smo inhibitor vismodegib (GDC-449) became available at the time of the study as an investigational drug, we decided to introduce vismodegib. Unrelated to Smo inhibitor treatment, patient 1 died of sepsis caused by urinary tract infection and patient 3 died of glioblastoma multiforme. In patient 2, even though the longest measurable diameter of the target lesion on the skin surface decreased by $13 \%$ and hence could be classified as stable disease, an unequivocal intrasellar progression was detected after 4 months. We further continued the IVA therapy and observed slow progression. Subsequently, the protocol was terminated due to the deterioration of the patient's general condition. Palliative radiotherapy was administered for the intrasellar invasion. The patient died soon 


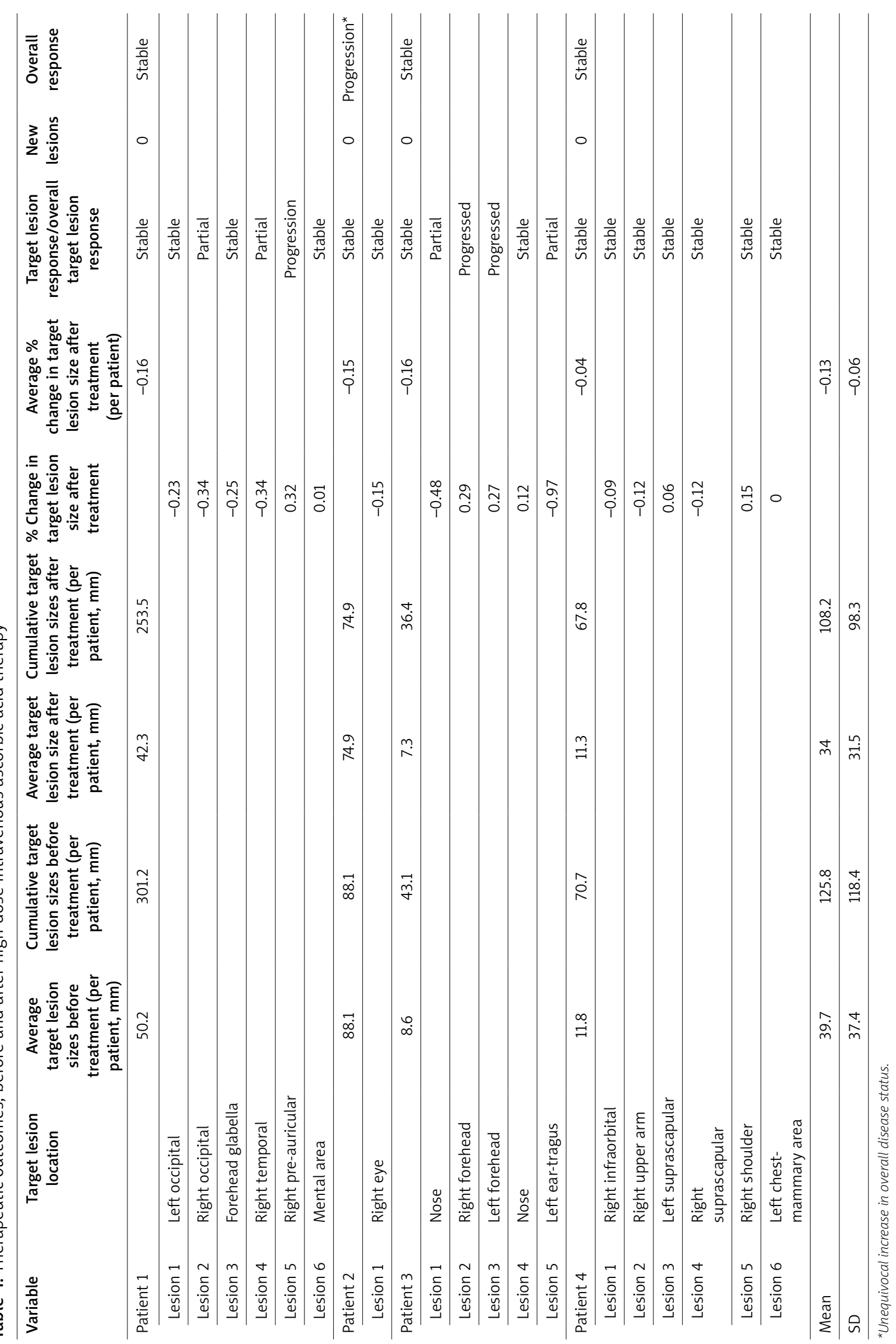


Table 5. Cutaneous score

\begin{tabular}{|c|c|c|c|c|c|c|c|c|}
\hline \multirow{2}{*}{$\begin{array}{l}\text { Achievable } \\
\text { score/per } \\
\text { each lesion } \\
\text { Horizontal/ } \\
\text { Vertical }\end{array}$} & \multicolumn{2}{|c|}{ Patient 1 ( $n=6$ lesions) } & \multicolumn{2}{|c|}{ Patient 2 ( $n=1$ lesion) } & \multicolumn{2}{|c|}{ Patient 3 ( $n=5$ lesions) } & \multicolumn{2}{|c|}{ Patient 4 ( $n=6$ lesions) } \\
\hline & $\begin{array}{l}\text { Horizontal } \\
\text { dimension }\end{array}$ & $\begin{array}{c}\text { Vertical } \\
\text { dimension }\end{array}$ & $\begin{array}{l}\text { Horizontal } \\
\text { dimension }\end{array}$ & $\begin{array}{c}\text { Vertical } \\
\text { dimension }\end{array}$ & $\begin{array}{l}\text { Horizontal } \\
\text { dimension }\end{array}$ & $\begin{array}{c}\text { Vertical } \\
\text { dimension }\end{array}$ & $\begin{array}{l}\text { Horizontal } \\
\text { dimension }\end{array}$ & $\begin{array}{c}\text { Vertical } \\
\text { dimension }\end{array}$ \\
\hline$-1 /-0.5$ & -1 & -0.5 & & & -2 & & & -0.5 \\
\hline $0 / 0$ & 0 & 0 & 0 & & & 0 & 0 & 0 \\
\hline $1 / 0.5$ & 2 & 1.5 & & 0.5 & 2 & 0.5 & & \\
\hline Average score & 0.17 & 0.17 & 0 & 0.5 & 0 & 0.1 & 0 & -0.08 \\
\hline Total score & \multicolumn{2}{|c|}{0.34} & \multicolumn{2}{|c|}{0.5} & \multicolumn{2}{|c|}{0.1} & -0.08 & \\
\hline
\end{tabular}
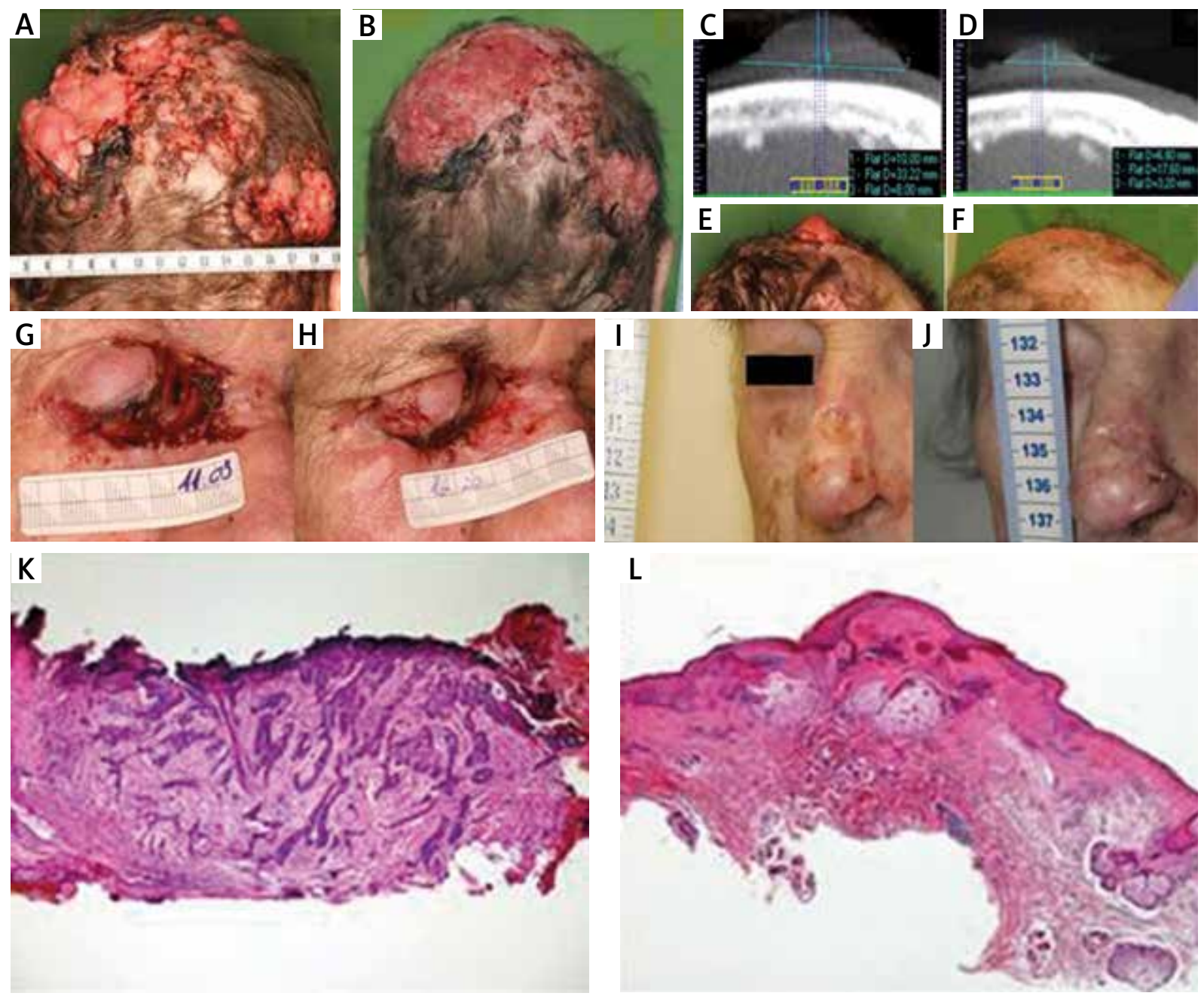

Figure 2. Locally advanced multiple basal cell carcinoma (BCC) before and after intravenous ascorbic acid (IVA) therapy at week $O(A)$ and week 75 (B) respectively. Computed tomography scans and photographs of a target lesion on the scalp before and after IVA therapy at week 0 (C, E) and week 75 (D, F) respectively. Locally advanced BCC involvement in the nasal and periorbital regions at week $9(\mathbf{G})$ and week $16(\mathrm{H})$ of IVA therapy. A target BCC lesion on the nose before and after IVA therapy at week $0(\mathrm{I})$ and week $26(\mathrm{~J})$, respectively. Hematoxylin and eosin $(\mathrm{H}+\mathrm{E})$ staining of a tissue sample from the nose before IVA therapy, infiltrative BCC $(K)$. HE staining of a tissue sample from the same region at the end of IVA therapy, scar tissue (L) 

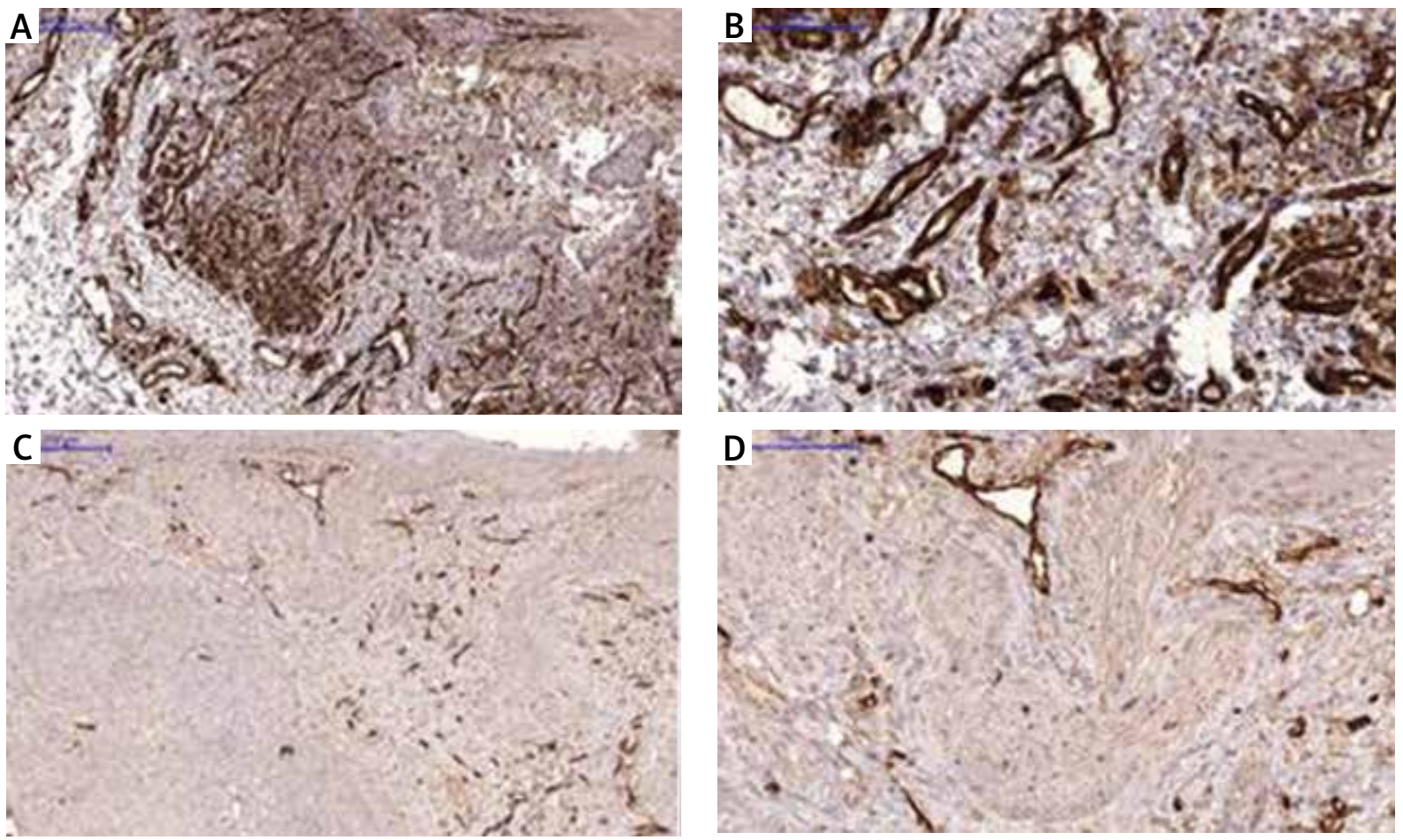

Figure 3. Micronodular basal cell carcinoma $(B C C)$ with high microvessel density in patient 1, magnification $140 \times($ A) and $400 \times(B)$. Adenoid BCC with low microvessel density in patient 1 magnification $140 \times$ (C) and 400× (D) (brown color indicates CD31 positivity)

after due to complications of irradiation therapy. Patient 4 dropped out from the study and we could not continue follow-up.

\section{Comparison of microvessel density by CD31 staining}

CD31, also known as platelet endothelial adhesion molecule, is a vascular endothelial cell marker, which correlates with microvessel density and tissue angiogenesis $[22,23]$. Studies show that microvessel density is generally higher in aggressive subtypes than those that are indolent $[24,25]$. Micronodular BCC is an aggressive subtype, while adenoid BCC is known to be an indolent variant [26]. We observed that in the case of patient 1 , most micronodular type BCC lesions showed a response to therapy, while the adenoid type lesion did not present any improvement (Figure 1). In an attempt to illustrate the differences of vascularization between the two subtypes, immunostaining with CD31 was performed for one micronodular and one adenoid lesion of the same patient. We observed a significantly higher level of microvessel density in the micronodular type of BCC compared to the adenoid type (Figure 3).

\section{Imaging of tumor collagen environment via two-} photon microscopy and second harmonic generation

We analyzed two micronodular lesions from patient 1 , one of which showed a stable response, and the other a partial response. Histologic features of BCC such as peripheral palisading cells and nests of basaloid cells (yellow) surrounded by parallelly aligned collagen fibers (magenta) could be identified by TPEF/SHG images (Figure 4). Tracking of collagen fibers by CT-FIRE revealed that following intense IVA treatment thinner and shorter collagen fibers could be observed between tumor nests and peritumoral stroma.

\section{Discussion}

Existing literature suggests that multiple pathways are targeted simultaneously when high-dose IVA is administered. Ascorbic acid is transported to the intracellular compartment mainly through sodium-dependent vitamin C transporter-2 (SVCT-2), glucose transporter-1 (GLUT-1) and GLUT-3 transporters [27, 28]. In tumor cells, upregulation of these channels, presumably due to their aptitude for glycolysis (Warburg effect) [29, 30], is a wellknown phenomenon and may lead to increased intracellular concentrations of ascorbic acid compared to normal cells [31-33]. Although ascorbic acid is historically known for its antioxidant properties, it was recently demonstrated that in the presence of catalytic iron, a pharmacologic dose of intravenously delivered ascorbic acid acts as a pro-oxidant, leading to the generation of hydrogen peroxide $\left(\mathrm{H}_{2} \mathrm{O}_{2}\right)$ and other reactive oxygen species (ROS) $[34,35]$. Chen et al. proposed that $\mathrm{H}_{2} \mathrm{O}_{2}$ generation may lead to deoxyribonucleic acid (DNA) damage and subse- 

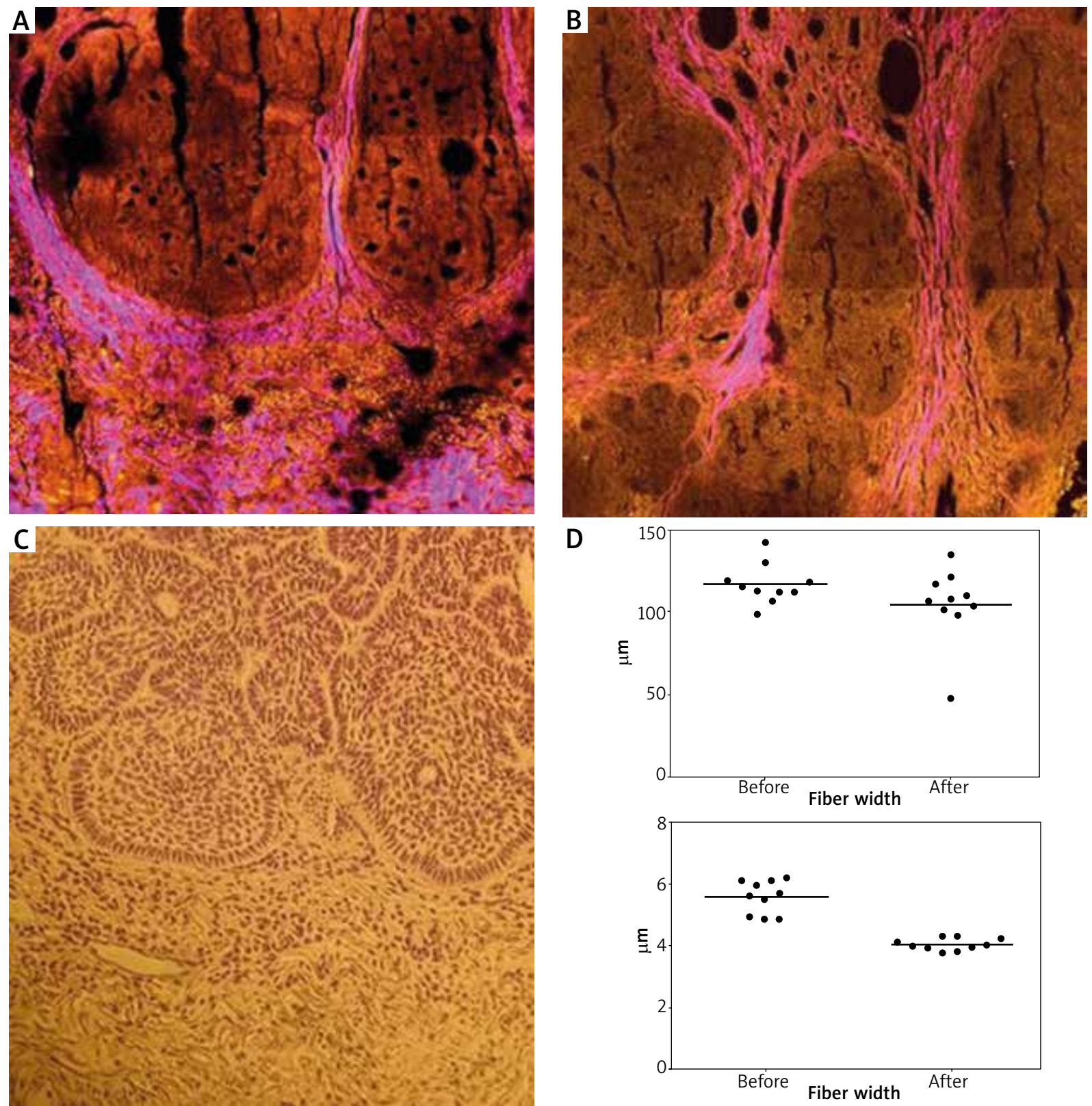

Figure 4. Two-photon excitation fluorescence (TPEF) and second harmonic generation images (SHG) from basal cell carcinoma (BCC) tissue samples of lesion 2 of patient 1. A - After a 2-week drug-free interval, B - after 2 weeks of intensive (10 sessions) intravenous ascorbic acid (IVA) therapy. TPEF signal of FAD is displayed in yellow, while SHG signal of collagen fibers is shown in magenta color. C - Hematoxylin and eosin stained section corresponding to the TPEF-SHG image shown in panel "A". D - Evaluation of mean length and width of collagen fibers from the SHG images before and after the abovementioned intensive IVA therapy period assessed by CT-FIRE (LOCI, USA) algorithm

quently activate poly-ADP-ribose polymerase (PARP). The latter utilizes oxidized nicotinamide adenine dinucleotide $\left(\mathrm{NAD}^{+}\right)$as a substrate, thereby depleting the source for reduced nicotinamide adenine dinucleotide (NADH) formation. Diminished levels of NADH will consequently decrease adenine trinucleotide phosphate (ATP) generation $[33,36-39]$. It was also postulated that $\mathrm{H}_{2} \mathrm{O}_{2}$ may directly damage the electron transport chain in the mitochondria, thus inhibiting the function of ATP synthase [37, 40]. ATP depletion could be further aggravated through exhaustion of the glutathione pathway, which takes part in the elimination of $\mathrm{H}_{2} \mathrm{O}_{2}[33,37]$. Ascorbic acid is also capable to release iron from ferritin, an acute-phase protein that is frequently elevated in cancer patients[41], providing an additional source of catalytic iron [42], further increasing the $\mathrm{H}_{2} \mathrm{O}_{2}$ production. 
It has been postulated that microvessel density, vascular endothelial growth factor (VEGF) expression and serum levels could correlate with invasiveness and aggressiveness of BCC [23-25, 43, 44]. In highly vascularized tissues, the tissue concentration of ascorbic acid and saturation of oxygen may reach higher levels. This could lead to increased ROS generation and subsequently an enhanced antitumor effect. This is consistent with the better therapeutic response that we observed in the case of most of the micronodular lesions for patient 1. On the other hand, the adenoid BCC lesion of patient 1 , which is an indolent subtype [26], did not show any improvement (Figure 1). This latter observation could be possibly explained by the low microvessel density of the adenoid lesion.

Studies suggest that alterations in collagen structure and orientation in tumor stroma can reflect cancer development, progression and/or metastasis [45-47]. For instance, when Conklin et al. used SHG to evaluate tissue biopsies from breast cancer patients, they observed a strong association between the number of collagen fibers aligned perpendicularly to the tumor boundary and patient survival [45]. We have previously reported that tumor stroma of BCC lesions had a significantly lower SHG signal intensity, reduced fiber angle, higher orientation of collagen and increased collagen fiber length [20]. Consistent with our previous finding, we have observed shortening of collagen fiber length after intense IVA therapy. After IVA treatment peritumoral collagen fiber width was also reduced. These results could be explained by the impaired production and the increased degradation of collagen structure due to IVA treatment.

To our best knowledge, this is the first report of administering IVA to treat locally advanced, incurable BCCs. Our results indicate that in properly selected patients with extensive BCCS, serial administration of IVA therapy is safe and relatively well tolerated, with mild and only transient side effects. The maximum tolerable dose and concentration via the peripheral vein was generally $75 \mathrm{~g} / 1000 \mathrm{ml}$ Ringer lactate (7.5\%), with the exception of patient 4, who could tolerate up to $100 \mathrm{~g}(10 \%)$ without a severe burning sensation. On the other hand, IVA alone does not seem to provide a dramatic and lasting therapeutic benefit. The requirement for multiple weekly patient visits and the length of each infusion also make this treatment somewhat impractical.

Our study has important limitations, such as a small sample size and the lack of a placebo controlled group. Patient 4 dropped out of the study and patient 3 was switched to vismodegib, both at a relatively early stage, preventing evaluation of a possible long-term beneficial effect. Last but not least, an ideal scoring system that accurately measures treatment response is still not available. Possibility of an unevenly higher reduction in vertical tumor dimensions compared to horizontal tumor dimensions or vice versa could lead to suboptimal tumor assessment. Beyond this, the illdefined lesion borders render both our adapted RECIST v1.1 criteria and cutaneous scoring system inadequate.

\section{Conclusions}

The first choice of treatment for locally advanced or metastatic BCC should be Smo inhibitor therapy, and IVA therapy could only be considered in treatment-resistant cases as an adjuvant therapy. However, even as an adjuvant, how ascorbic acid interacts with a Smo inhibitor and whether this interaction may hinder or potentiate the effects of Smo inhibitors need to be investigated.

\section{Acknowledgments}

Sarolta Kárpáti and Krisztián Németh are considered co-last authors. This work was supported by the National Research, Development and Innovation Fund [K-129047, 2018], Hungarian Scientific Research Fund (NOTKA 114460) and the Semmelweis University Dean's Research Award 2015.

We are grateful for the insightful discussions and treatment protocols to Dr. Mark Levine, NIDDK, National Institutes of Health, Bethesda, MD, USA; Barbara Boston, George Washington Center for Integrative Medicine, Washington DC USA; and Dr. Jeannette Drisko, Department of Internal Medicine, Division of KU Integrative Medicine, Kansas City, Kansas.

We are also indebted to Dr. Miklós Sárdy for critical review of the manuscript, and to Prof Dr. Romana Zelko and Dr. Gábor Bartus for their assistance with the preparation of the ascorbic acid solutions. We further acknowledge the help of Dr. Judit Hársing for reading of the histology slides and Szabolcs Bozsányi for his technical assistance during the TPEF and SHG imaging process.

\section{Conflict of interest}

Dr. Szipőcs holds shares in R\&D Ultrafast Lasers Ltd. The remaining authors declare no conflict of interest.

\section{References}

1. Leiter U, Garbe C. Epidemiology of melanoma and nonmelanoma skin cancer: the role of sunlight. Adv Exp Med Biol 2008; 624: 89-103.

2. Sekulic A, Migden MR, Lewis K, et al. Pivotal ERIVANCE basal cell carcinoma (BCC) study: 12-month update of efficacy and safety of vismodegib in advanced BCC. J Am Acad Dermatol 2015; 72: 1021-6e8.

3. Mohan SV, Chang AL Advanced basal cell carcinoma: epidemiology and therapeutic innovations. Curr Dermatol Rep 2014; 3: 40-5.

4. Migden MR, Guminski A, Gutzmer R, et al. Treatment with two different doses of sonidegib in patients with locally advanced or metastatic basal cell carcinoma (BOLT): a multicentre, randomised, double-blind phase 2 trial. Lancet Oncol 2015; 16: 716-28.

5. Chen L, Aria AB, Silapunt S, et al. Treatment of advanced basal cell carcinoma with sonidegib: perspective from the 30-month update of the BOLT trial. Future Oncol 2018; 14: 515-25.

6. Dessinioti C, Plaka M, Stratigos AJ. Vismodegib for the treatment of basal cell carcinoma: results and implications of the ERIVANCE BCC trial. Future Oncol 2014; 10: 927-36. 
7. Sekulic A, Migden MR, Oro AE, et al. Efficacy and safety of vismodegib in advanced basal-cell carcinoma. N Engl I Med 2012; 366: 2171-9.

8. Ridky TW, Cotsarelis G. Vismodegib resistance in basal cell carcinoma: not a smooth fit. Cancer Cell 2015; 27: 315-6.

9. Fritz H, Flower G, Weeks L, et al. Intravenous vitamin C and cancer: a systematic review. Integr Cancer Ther 2014; 13: 280-300.

10. Riordan HD, Casciari JJ, Gonzalez MJ, et al. A pilot clinical study of continuous intravenous ascorbate in terminal cancer patients. $P$ R Health Sci I 2005; 24: 269-76.

11. Hoffer LJ, Levine M, Assouline S, et al. Phase I clinical trial of i.v. ascorbic acid in advanced malignancy. Ann Oncol 2008; 19: 1969-74.

12. Stephenson CM, Levin RD, Spector T, Lis CG. Phase I clinical tria to evaluate the safety, tolerability, and pharmacokinetics of highdose intravenous ascorbic acid in patients with advanced cancer. Cancer Chemother Pharmacol 2013; 72: 139-46.

13. Hollo P, Jokai H, Harsing J, et al. Topically applied ascorbic acid solution for the treatment of basal cell carcinoma (BCC). J Am Acad Dermatol 2016; 75: 212-3.

14. Heuke S, Vogler N, Meyer T, et al. Detection and discrimination of non-melanoma skin cancer by multimodal imaging. Healthcare (Basel, Switzerland) 2013; 1: 64-83.

15. Balu M, Zachary CB, Harris RM, et al. In vivo multiphoton microscopy of basal cell carcinoma. JAMA Dermatol 2015; 151: 1068-74.

16. Bree AF, Shah MR, Group BC. Consensus statement from the first international colloquium on basal cell nevus syndrome (BCNS). Am J Med Genet A 2011; 155A: 2091-7.

17. Eisenhauer EA, Therasse P, Bogaerts J, et al. New response evaluation criteria in solid tumours: revised RECIST guideline (version 1.1.). Eur J Cancer 2009; 45: 228-47.

18. Mashiah J, Harel A, Bodemer C, et al. Topical pimecrolimus for paediatric cutaneous mastocytosis. Clin Exp Dermatol 2018; 43 559-65.

19. Maytin EV, Kaw U, llyas M, et al. Blue light versus red light for photodynamic therapy of basal cell carcinoma in patients with Gorlin syndrome: a bilaterally controlled comparison study. Photodiagnosis Photodyn Ther 2018; 22: 7-13.

20. Kiss N, Haluszka D, Lorincz K, et al. Quantitative analysis on ex vivo nonlinear microscopy images of basal cell carcinoma samples in comparison to healthy skin. Pathol Oncol Res 2018. doi: 10.1007/s12253-018-0445-1.

21. Haluszka D, Lorincz K, Kiss N, et al. Diet-induced obesity skin changes monitored by in vivo SHG and ex vivo CARS microscopy. Biomed Optics Express 2016; 7: 4480-9.

22. Cheng SH, Liu JM, Liu QY, et al. Prognostic role of microvessel density in patients with renal cell carcinoma: a meta-analysis. Int J Clin Exp Pathol 2014; 7: 5855-63.

23. Staibano S, Boscaino A, Salvatore G, et al. The prognostic significance of tumor angiogenesis in nonaggressive and aggressive basal cell carcinoma of the human skin. Hum Pathol 1996; 27: 695-700.

24. Loggini B, Boldrini L, Gisfredi S, et al. CD34 microvessel density and VEGF expression in basal and squamous cell carcinoma. Pathol Res Pract 2003; 199: 705-12.

25. Carbone A, Viola P, Varrati S, et al. Microvessel density and VEGF expression seems to correlate with invasiveness of basal cell carcinoma. Eur J Dermatol 2011; 21: 608-9.

26. Murkey N, Murkey P, Kalele KP, Patil KP. Adenoid variant of basal cell carcinoma: a case report with a glance at biological behavior of the tumor. Indian J Dermatol 2017; 62: 103-5.

27. Tsukaguchi H, Tokui T, Mackenzie B, et al. A family of mammalian $\mathrm{Nat-dependent} \mathrm{L-ascorbic} \mathrm{acid} \mathrm{transporters.} \mathrm{Nature} \mathrm{1999;} \mathrm{399:}$ 70-5.
28. Vera JC, Rivas Cl, Fischbarg J, Golde DW. Mammalian facilitative hexose transporters mediate the transport of dehydroascorbic acid. Nature 1993; 364: 79-82.

29. Warburg O. On the origin of cancer cells. Science 1956; 123: 309-14.

30. Hsu PP, Sabatini DM. Cancer cell metabolism: Warburg and beyond. Cell 2008; 134: 703-7.

31. Krzeslak A, Wojcik-Krowiranda K, Forma E, et al. Expression of GLUT1 and GLUT3 glucose transporters in endometrial and breast cancers. Pathol Oncol Res 2012; 18: 721-8.

32. Macheda ML, Rogers S, Best JD. Molecular and cellular regulation of glucose transporter (GLUT) proteins in cancer. J Cell Physiol 2005; 202: 654-62.

33. Yun J, Mullarky E, Lu C, et al. Vitamin C selectively kills KRAS and BRAF mutant colorectal cancer cells by targeting GAPDH. Science 2015; 350: 1391-6.

34. Du J, Cullen JJ, Buettner GR. Ascorbic acid: chemistry, biology and the treatment of cancer. Biochim Biophys Acta 2012; 1826: 443-57.

35. Vilcheze C, Hartman T, Weinrick B, Jacobs WR Jr. Mycobacterium tuberculosis is extraordinarily sensitive to killing by a vitamin Cinduced Fenton reaction. Nat Commun 2013; 4: 1881.

36. Verrax J, Vanbever S, Stockis J, et al. Role of glycolysis inhibition and poly(ADP-ribose) polymerase activation in necrotic-like cell death caused by ascorbate/menadione-induced oxidative stress in K562 human chronic myelogenous leukemic cells. Int J Cancer 2007; 120: 1192-7.

37. Chen P, Yu J, Chalmers B, et al. Pharmacological ascorbate induces cytotoxicity in prostate cancer cells through ATP depletion and induction of autophagy. Anticancer Drugs 2012; 23: 437-44.

38. Lee YJ, Shacter E. Oxidative stress inhibits apoptosis in human lymphoma cells. J Biol Chem 1999; 274: 19792-8.

39. Schraufstatter IU, Hinshaw DB, Hyslop PA, et al. Oxidant injury of cells. DNA strand-breaks activate polyadenosine diphosphateribose polymerase and lead to depletion of nicotinamide adenine dinucleotide. J Clin Invest 1986; 77: 1312-20.

40. Ahmad IM, Aykin-Burns N, Sim JE, et al. Mitochondrial O2*- and H2O2 mediate glucose deprivation-induced stress in human cancer cells. J Biol Chem 2005; 280: 4254-63.

41. Alkhateeb AA, Connor JR. The significance of ferritin in cancer: anti-oxidation, inflammation and tumorigenesis. Biochim Biophys Acta 2013; 1836: 245-54

42. Baader SL, Bruchelt G, Carmine TC, et al. Ascorbic-acid-mediated iron release from cellular ferritin and its relation to the formation of DNA strand breaks in neuroblastoma cells. J Cancer Res Clin Oncol 1994; 120: 415-21.

43. Bowden J, Brennan PA, Umar T, Cronin A. Expression of vascular endothelial growth factor in basal cell carcinoma and cutaneous squamous cell carcinoma of the head and neck. J Cutan Pathol 2002; 29: 585-9.

44. Sobjanek M, Zablotna M, Lesiak A, et al. The -1154 G/A VEGF gene polymorphism is associated with the incidence of basal cell carcinoma in patients from northern Poland. Arch Dermatol Res 2014; 306: 539-44.

45. Conklin MW, Eickhoff JC, Riching KM, et al. Aligned collagen is a prognostic signature for survival in human breast carcinoma. Am J Pathol 2011; 178: 1221-32.

46. Kirkpatrick ND, Brewer MA, Utzinger U. Endogenous optical biomarkers of ovarian cancer evaluated with multiphoton microscopy. Cancer Epidemiol Biomarkers Prev 2007; 16: 2048-57.

47. Perry SW, Burke RM, Brown EB. Two-photon and second harmonic microscopy in clinical and translational cancer research. Ann Biomed Eng 2012; 40: 277-91. 